\title{
Hacia una justicia sin derecho: la justicia de la memoria*
}

\author{
Towards a justice without law: justice of memory
}

Para uma justiça sem direito: a justiça da memória

Fecha de entrega: 30 de agosto de 2012

Fecha de evaluación: 31 de octubre de 2012

Fecha de aprobación: 6 de diciembre de $2012^{\circ}$

Adriana María Ruiz Gutiérrez ${ }^{* *}$

\section{Resumen}

La memoria es el principio de la justicia que permite destruir el vínculo entre el poder y la violencia que funda y mantiene el orden del derecho. La justicia de la memoria es, en efecto, una fuerza revolucionaria que anuncia el sufrimiento de los oprimidos, de los vencidos, de los sojuzgados de la historia; es una especie de antihistoria que se rebela ante el poder que somete la vida natural a un estado de excepción permanente; es una justa apelación a la justicia más allá del derecho que permite instaurar un nuevo orden fundado en la vida como potencia y como vida justa.

* El presente artículo hace parte de los estudios que la autora realiza en el campo de la filosofía del derecho, en particular sobre la relación entre la violencia y la justicia.

* Abogada y magister en Filosofía Contemporánea de la Universidad de Antioquia. En la actualidad realiza el Doctorado en Derecho en la Universidad Santo Tomás, institución en el que trabaja como docente en la Facultad de Derecho, sede Medellin, y desarrolla una investigación sobre el tema de la reparación y la justicia en la población femenina. Correo electrónico: adrianaruiz@iner.udea.edu.co 
Palabras clave: Pascal, Benjamin, poder, violencia, derecho, violencia mítica, violencia divina, justicia de la memoria.

\section{Abstract}

Memory is the principle of justice which allows destroying the vehicle between power and violence that establishes and maintains the order of law. Justice of the memory is, indeed, a revolutionary force that announces the suffering of the oppressed, the defeated, the subjugated in history; it is a kind of anti-history that rebels against the power that submits natural life to a permanent state of exception; it is a fair appeal to justice beyond the law which allows the introduction of a new order founded in life as power and fair life.

Keywords: Pascal, Benjamin, power, violence, law, mythical violence, divine violence, justice of the memory.

\section{Resumo}

A memória é o princípio da justiça que permite destruir a relação entre o poder e a violência que funda e mantém a ordem do direito. A justiça da memória é, de fato, uma força revolucionária que anuncia o sofrimento dos oprimidos, dos vencidos, dos subjugados da história; é uma espécie de anti-história que rebela-se diante do poder que submete a vida natural a um estado de exceção permanente; é uma justa apelação à justiça além do direito que permite a introdução de uma nova ordem fundada na vida como potencia e como vida justa.

Palavras-chave: Pascal, Benjamin, poder, violência, direito, violência mítica, violência divina, justiça da memória. 


\section{Introducción}

La responsabilidad ante la memoria histórica es excesiva e incalculable. De ahí la tarea de estudiar críticamente el origen, el sentido y, por tanto, los límites de los conceptos de justicia y de derecho. En efecto, la tarea de una memoria histórica pasa por la crítica al derecho como forma de un control violento sobre la vida, distinta a la justicia infinita, incalculable y, por ende, extraña a la práctica de la justicia legal. El derecho no es la justicia. En las críticas de Pascal y Benjamin, toda fuerza es, como medio, poder que funda y mantiene el derecho. Uno y otro coinciden en proponer una justicia que no solo excede o contraría al derecho, sino que se presenta de un modo verdaderamente destructor respecto al orden jurídico: una justicia más allá del campo de los vencedores y más acá de las manos de Dios como justo perfecto.

Esta justicia pretende, a diferencia de la justicia distributiva y conmutativa aristotélica fundada en la igualdad, reivindicar mediante la memoria el sufrimiento de aquellos que han vivido en un estado de excepción permanente. Por supuesto, la justicia de la memoria que exigen los oprimidos no tiene lugar en el derecho, donde el vencedor asume una posición que resulta ya inamovible respecto a los vencidos, lo que concluye finalmente en la instauración de un nuevo "derecho" reconocido al ganador, con independencia de todos los vencidos. El camino que conduce a la justicia de la memoria no pasa, entonces, por las instituciones jurídicas, sino por otras manifestaciones puras, no jurídicas y, por ende, subversivas respecto al poder de la sumisión y del olvido.

\section{Pascal: la justicia como derecho y la fuerza}

"El derecho puede ser válido sin ser justo, y por ello no deja de ser derecho". Este enunciado de la teoría jurídica positivista significa que la justicia no es necesariamente el derecho y que, en consecuencia, no puede convertirse en justicia de derecho si no apela a la fuerza desde su origen. La fuerza empleada como medio es siempre o bien fundadora de derecho, o bien conservadora de derecho; en caso de no pretender alguno de estos dos atributos, renuncia por sí misma a toda validez. El derecho es, pues, inseparable de la violencia. De esta forma, una institución de derecho se debilita cuando su conciencia ignora la presencia latente de la violencia que la habita. Las instituciones jurídico-políticas existen, consideradas tanto en sus orígenes como en sus fines, gracias a órdenes de derecho armados de 
violencia (Benjamin, 2001, p. 117). Esta crítica de autoría benjaminiana conserva, no obstante, un eco precedente en el filósofo cristiano y racionalista Blaise Pascal. Según Sorel (2005), Pascal fue el filósofo que supo emanciparse por primera vez de la tradición del derecho natural medieval como derecho justo:

Fragmento 375. He pasado una gran parte de la vida creyendo que había una justicia y en esto no me equivocaba, porque la hay tal como Dios nos la ha querido revelar, pero yo no lo tomaba así y es en lo que me equivocaba, porque creía que nuestra justicia era esencialmente justa y que yo tenía con qué conocerla y juzgarla (Pascal, 1981, p. 518).

Por eso, y después de muchos cambios de juicio relativos a la verdadera justicia, escribe Pascal (2009): "He reconocido que nuestra naturaleza no era sino un continuo cambio" (p. 97), porque "así como la moda crea los adornos, también crea la justicia" (Pascal, 1981, p. 369). Y puesto que todos los países y todos los hombres son mudables, se sigue que la justicia no se encuentra en las leyes naturales conocidas en todo lugar - pues no existe una sola ley humana que sea universal-, sino en las costumbres. Según Sorel (2005), estas observaciones le demostraron a Pascal lo absurdo de la teoría del derecho natural, pues si esa teoría era exacta, habría unas leyes universales admitidas; empero, ciertas acciones que se consideran crímenes han sido contempladas en otros tiempos como acciones virtuosas (Sorel, 2005, pp. 77-78), y lo que antes era justo pasa a ser injusto: "El latrocinio, el incesto, el asesinato de hijos y de padres, todo ha sido reconocido entre las acciones virtuosas" (Pascal, 2009, p. 85).

Conceder lo contrario, esto es, que la justicia no se encuentra en las costumbres, sino que reside en las leyes naturales universales, conduce a una grave confusión: "Sucede que el uno dice que la esencia de la justicia es la autoridad del legislador; el otro, la comodidad del soberano; otro, la costumbre presente" (Pascal, 2009, p. 85). Y esta última es lo más seguro, pues "nada es justo en sí según la sola razón; todo se vacila con el tiempo. La costumbre constituye toda la equidad, sin más razón que la de ser recibida" (Pascal, 2009, p. 85). La costumbre es, pues, según Pascal (2009), la que determina el valor de las acciones:

Tres grados de elevación hacia el polo echan por tierra toda la jurisprudencia, un meridiano decide la verdad. En todos los Estados del mundo, y en todos 
los tiempos, nada hay justo o injusto que no cambie de cualidad cambiando el clima (Pascal, 2009, p. 85).

En palabras del pensador, la jurisdicción en ningún caso se da para el jurisdiciante, sino para la juridicidad en sí misma. Pero esto es peligroso decírselo al pueblo que respeta las leyes en tanto las considera justas, “[pues] obedece a la justicia que imagina, pero no a la esencia de la ley; está todo ello reconcentrado en sí. Es la ley y nada más" (Pascal, 2009, p. 86). Del mismo modo como ocurre con las leyes, así también sucede con el poder, la fuerza o la autoridad del soberano:

Fragmento 308. La costumbre de ver a los reyes acompañados de guardias, de tambores, de oficiales y de todas las cosas que inclinan a la máquina al respeto $\mathrm{y}$ al terror hace que sus rostros, cuando se hallan a veces solos y sin sus acompañantes, impriman en sus súbditos el respeto y el terror, porque no separamos nuestro pensamiento de sus personas de sus séquitos que suelen verse juntos. Y el mundo que no sabe que este efecto procede de esa costumbre, cree que viene de una fuerza natural. Y de ahí vienen estas palabras: "el carácter de la divinidad está impreso en su rostro" (Pascal, 2009, p. 88).

Por esta razón, Montaigne se ha equivocado, en palabras de Pascal (2009): "La costumbre solo debe ser seguida porque es costumbre, y no porque sea razonable o justa, pero el pueblo la sigue por la única razón de que la cree justa” (p. 90). Según Pascal, convendría, en cambio, que el pueblo obedeciera las leyes y las costumbres porque son leyes, y nada más. De este modo no se sublevaría nunca, pero quizás, y al mismo tiempo, no querría someterse a ellas y buscaría siempre la verdadera justicia. De esta manera, escribe Pascal que es útil saber que no hay ninguna ley humana verdadera y justa, en tanto no conocemos nada; por tanto, tenemos que limitarnos a seguir las leyes recibidas, y así no las abandonaríamos nunca. Sin embargo, el pueblo no es accesible a esta doctrina:

Y así como cree que la verdad puede encontrarse y que se halla en las leyes y en las costumbres, él las cree y considera su antigüedad como una prueba de su verdad (y no solamente de su autoridad [temeraria] sin razón o verdad) (Pascal, 2009, p. 90). 
Es peligroso decirle al pueblo que las leyes no son justas, porque puede sublevarse contra ellas: "El pueblo se encuentra siempre sometido a desobedecer en cuanto se le muestre que las leyes no valen nada, lo cual puede hacerse ver de todas, considerándolas de un cierto lado" (Pascal, 2009, p. 90). De esta manera, dice el filósofo:

[Al pueblo] hay que decir que [obedezca] a las leyes porque son leyes, como hay que obedecer a los superiores no porque son justos, sino porque son superiores. Con ello se previene la sedición, que es propiamente la definición de la justicia como derecho (p. 91).

En suma, las leyes no son justas en sí mismas, sino que lo son por ser leyes; en consecuencia, dice Pascal (1981): "La justicia es lo que está establecido, y así, todas nuestras leyes establecidas serán necesariamente consideradas justas sin previo examen, puesto que están establecidas. Es el fundamento místico de su autoridad" (p. 542). Quien retrotraiga las leyes a su origen, las destruye, porque "no hay nada tan culpable como esas leyes que corrigen las culpas” (Pascal, 2009, p. 86). Esta afirmación anticipa la crítica de Benjamin a la violencia del derecho, justamente porque la crítica pascaliana se define como la posibilidad de hacer tambalear las costumbres establecidas, de derribar los Estados, profundizando hasta sus orígenes a fin de mostrar su falta de autoridad y de justicia (Pascal, 2009, p. 86).

Pascal omite las referencias de Montaigne al escribir sobre el fundamento místico de la autoridad. Justamente, Montaigne escribió en su ensayo titulado "La experiencia" que las leyes mantienen su crédito no porque sean justas, sino porque son leyes: "Este es el fundamento místico de su autoridad, no tiene otro, lo cual les conviene mucho"; porque las leyes, agrega Montaigne (2007), “a menudo están hechas por necios, las más de las veces por gente que, por odio a la igualdad, carece de equidad, pero siempre por hombres, autores vanos e inciertos". En consecuencia, "nada es tan grave, extensa y habitualmente falible como las leyes. Quien las obedezca porque son justas, no las obedece justamente por el motivo correcto" (Montaigne, 2007, pp. 1601-1602). De esta manera, el autor distingue entre el derecho como justicia y la justicia. La justicia legal, la justicia del derecho, la justicia como derecho no es justicia. Las leyes no son justas en tanto leyes; por consiguiente, no se obedecen porque sean justas, sino porque tienen fuerza, poder, autoridad. En otras palabras, la autoridad de las leyes solo reside sobre el crédito que se les otorga: simplemente se cree en ellas. Ese es precisamente el fundamento místico de su autoridad (Derrida, 2002, pp. 25-29). 
En el intento por comprender la expresión "fundamento místico de la autoridad", Derrida acude a la semejanza propuesta por Montaigne entre un artificio de mujer, que a la vista y a sabiendas de todos se adorna con una belleza falsa y prestada, y la ficción del derecho sobre la que funda la verdad de la justicia:

Así como las mujeres usan dientes de marfil cuando les faltan los suyos y, en lugar de su verdadera tez, se forman una con alguna materia extraña, se hacen muslos de paño y de fieltro y se añaden carnes con algodón, así también el derecho ofrece razones y respuestas que él mismo nos enseña que son inventadas (Montaigne, 2008, p. 799).

Según Derrida (2002), la analogía propuesta por Montaigne entre este suplemento de ficción legítima, destinado a fundar la verdad de la justicia y el suplemento de artificio necesario originado por una deficiencia de la naturaleza, pareciese indicar que la ausencia de derecho natural requiere el suplemento de derecho histórico o positivo, esto es, un suplemento de ficción (Derrida, 2002, p. 30).

Pascal (1981) llega más lejos y demuestra, además, cómo lo justo-legal depende de la fuerza: "Es justo que lo que es justo sea obedecido, es necesario que lo que es más fuerte sea obedecido. La justicia sin la fuerza es desobedecida, porque siempre hay malos. La fuerza sin la justicia es discutida" (p. 377). Por consiguiente, "hay que poner juntas la justicia y la fuerza, y para ello hacer que lo que es justo sea fuerte, o que lo que es fuerte sea justo (p. 377). Mientras que Agustín de Hipona y Tomás de Aquino "ponen juntas" la justicia y el derecho, Pascal "pone juntas" la justicia como derecho y la fuerza, y hace de la fuerza una especie de predicado no accidental, sino esencial de la justicia. La justicia legal reclama, pues, el recurso a la fuerza; por ello, y a la vez, el uso de la fuerza está contenido en lo justo de la justicia, en el sentido del derecho. O acaso, pregunta Pascal (1981), “¿por qué se obedece a la pluralidad? ¿Porque tienen más razón? No, sino más fuerza” (p. 553). Esto nos recuerda siempre que si la justicia no es ineludiblemente el derecho o la ley; aquella no puede convertirse en justicia legal si no apela a la fuerza desde su primer instante.

Según Derrida (2002), en el principio de la justicia habrá habido lógos, lenguaje o lengua, lo que no estaría necesariamente en desacuerdo con otro íncipit que indicara: "En el principio habrá habido fuerza" (p. 25), porque la ley existe en virtud de la aplicabilidad y, al mismo tiempo, preexiste la aplicabilidad en tanto coexiste la 
fuerza, sea esta directa o no, física o simbólica, exterior o interior, brutal o sutilmente discursiva $-\mathrm{o}$ incluso hermenéutica-, coercitiva o regulativa (Derrida, 2002, pp. 16-17). Incluso, y más allá de la comprensión de la ley como un "poder enmascarado”, más allá de la moral cínica de El lobo y el cordero de La Fontaine con arreglo a la cual "la razón del más fuerte es siempre la mejor", y más acá, en la esencia, en lo más íntimo de la crítica pascaliana a la justicia como derecho en su relación con la fuerza, se esconde, según Derrida (2002), una estructura más intrínseca, a saber: el origen mismo de la justicia como derecho: la ley. El acontecimiento instituyente, fundador y justificador del derecho - que, por otra parte, nunca es un acontecimiento inscrito en el tejido homogéneo de una historia, pues lo que hace es rasgarlo con una decisión-, implica siempre e inevitablemente una fuerza realizativa, esto es, una fuerza interpretativa que no es justa ni injusta en sí misma, ni legal ni ilegal, en tanto que ninguna justicia ni ningún derecho anterior y fundador podría garantizar, contradecir o invalidar por definición (Derrida, 2002, pp. 31-33).

En suma, la operación que consiste en crear, instituir, justificar el derecho, hacer la ley, consistiría en un golpe de fuerza que no pudo haber sido autorizada por una legitimidad anterior; no obstante, dicha violencia no es en ese momento inicial ni legal, ni ilegal, ni justa, ni injusta; no es, por ende, un llamado a la creencia en la justicia como derecho, en tanto acto de fe ni lógico ni ontológico, sino místico. Al respecto, señala Derrida (2002):

Esta vez el derecho no estaría al servicio de la fuerza, como un instrumento dócil, servil y por tanto exterior del poder dominante, sino que el derecho tendría una relación más interna y compleja con lo que se llama fuerza, poder o violencia (p. 25).

En el silencio encerrado en la estructura violenta del acto de fundación o de institución de la justicia como derecho consiste, pues, la interpretación derridiana de la expresión que Montaigne y Pascal llaman "fundamento místico de la autoridad". Y porque en definitiva el origen de la autoridad, la fundación, el fundamento o la posición de la ley solo pueden, por definición, apoyarse en ellos mismos, constituyen en sí mismos una violencia sin fundamento. Ello no implica, sin embargo, y en palabras de Derrida (2002), que sean injustos en sí, en el sentido de "ilegales" o "ilegítimos" (pp. 33-34). 
Sorel y Derrida advierten en Pascal -y particularmente en el pasaje que "pone juntas" la fuerza y la justicia - no solo la crítica al derecho natural, sino también, en general, a la ideología jurídica que pretende equiparar la justicia - en el sentido del derecho- y la fuerza en una relación de íntima necesidad:

No se han ahorrado sofismas para demostrar que la fuerza había sido puesta al servicio de la justicia durante las revoluciones, se ha demostrado que esos argumentos son absurdos, pero la gente no puede resignarse a abandonarlos, ya que está acostumbrada a creer en el derecho natural (Sorel, 2005, pp. 78-79).

Y es por ello, justamente, que "un sistema social bien coordinado es destruido por una revolución que da paso a otro sistema juzgado igualmente razonable. Y aquello que era justo pasa a ser injusto" (Sorel, 2005, pp. 78-79). Por su parte, Derrida (2002) concluye:

En Pascal y Montaigne podemos hallar las premisas de una filosofía crítica moderna, de una crítica de la ideología jurídica, una desedimentación de las superestructuras del derecho que esconden y reflejan los intereses económicos y políticos de las fuerzas dominantes de la sociedad (p. 32).

De esta manera, y según Derrida, la justicia como derecho no estaría meramente al favor de una fuerza o de un poder social, económico, político o ideológico, sino que tendría una relación más interna y compleja con aquella.

\section{Benjamin: la violencia mítica y la violencia de Dios}

En el ensayo de Benjamin titulado "Para una crítica de la violencia" (Zur Kritik der Gewalt, 1921), el término "crítica" no significa juicio negativo, reproche o condena de la violencia, sino juicio, examen, evaluación de los medios para juzgar la violencia. En sentido exacto, la palabra alemana Gewalt se traduce como "violencia”, pero también denota para los alemanes "poder legítimo", “autoridad justificada”, "fuerza pública" - Gesetzgebende Gewalt es el poder legislativo; geistliche Gewalt, el poder espiritual de la Iglesia; Staatsgewalt, la autoridad o el poder del Estado-. Luego, la llamada "violencia natural" o "violencia física" - como causa de un fenómeno de la naturaleza o de un dolor corporal, entre otros- no permite una crítica del 
concepto de violencia, puesto que no se trata de una Gewalt que dé lugar a un juicio. La violencia pertenece, por tanto, a la esfera simbólica de lo jurídico, lo político y lo moral, a todas las formas de autoridad o de autorización, o al menos de voluntad a la autoridad, como señala Derrida (2002, pp. 18, 83). Y es únicamente en la esfera de estas relaciones que se comprende la crítica del concepto de violencia, como explica Benjamin (2001): "La tarea de una crítica de la violencia puede definirse como la exposición de su relación con el derecho y la justicia, sobre todo en lo que respecta al primero de estos dos conceptos" (p. 109).

Según Benjamin (2001), la crítica tiene una conexión con el derecho, principalmente, porque los criterios para la evaluación de la violencia pueden encontrarse en el reino de los fines y de los medios, y esta es, justamente, la relación fundamental y más elemental de todo orden jurídico: derecho natural y derecho positivo (p. 109). El derecho natural encuentra en el reino de los fines el criterio para evaluar la violencia; en este caso, basta considerar si la violencia sirve como medio para fines justos o injustos. Pero no es así. Benjamin acusa estos fundamentos de servir tan solo como criterios de definición en los casos de aplicación de la violencia en un sistema de fines justos que, además de llevar el problema de la violencia a un casuismo sin fin, no conduciría a la crítica de la violencia misma, en sí misma, como medio justo o injusto, moral o inmoral (Benjamin, 2001, p. 110; Derrida, 2002, pp. 18, 83). Por tanto, la cuestión de si la violencia es en general moral, aun cuando sea un medio para fines justos, permanecería, entonces, sin respuesta (Benjamin, 2001, p. 109).

Benjamin (2001), en consecuencia, propone otro criterio para la evaluación de la violencia misma como principio, una distinción en la esfera de los medios, independientemente de los fines a los que sirven: "La violencia, para comenzar, solo puede ser buscada en el reino de los medios y no de los fines" (p. 109). Y dado que la justicia es el criterio de los fines, y la legalidad es el criterio de los medios, en Benjamin la tesis del derecho natural de la violencia como dato naturalmente dado es diametralmente opuesta a la posición del derecho positivo, que considera a la violencia en su devenir histórico. De ahí que el derecho natural pueda considerar juicios críticos de la violencia sobre todo derecho existente solo en vista de sus fines, y que el derecho positivo pueda obtener juicios de la violencia sobre todo derecho en vías de su transformación únicamente a partir de la crítica de sus medios.

Así como el derecho natural está ciego respecto al condicionamiento de los medios, el derecho positivo lo está en materia de incondicionalidad de los fines. No obstante, 
y sin obviar las oposiciones, ambas teorías comparten un dogma fundamental, tal como lo explica Benjamin (2001): los fines justos pueden ser alcanzados por medios legítimos, y a la par, los medios legítimos pueden ser utilizados al servicio de fines justos. Por consiguiente, el derecho natural aspira a "justificar" los medios por la justicia de sus fines; y el derecho positivo, en cambio, intenta "garantizar" la justicia de los fines por la legitimación de los medios (p. 110). Esta antinomia, no obstante, resulta insoluble cuando medios legítimos y fines justos se encuentran mutuamente en irreconciliable contradicción; por lo mismo, justamente, la verdad del dogma común entre el derecho positivo y el derecho natural podría ser falseada.

Pero dice Benjamin (2001): “Nunca se logrará llegar a esta comprensión mientras no se abandone el círculo y no se establezcan criterios independientes para fines justos y para medios legítimos" (p. 110). Este criterio, sin embargo, no se encuentra ni en la tradición positiva del derecho ni en la tradición del derecho natural; por tanto, Benjamin pretende exceder ambas tradiciones al localizar su investigación crítica en una consideración histórico-filosófica del derecho, a fin de no depender ni del orden jurídico ni de la interpretación interna de la institución jurídica (p. 111). En palabras de Derrida, tan audaces y necesarias como las de Benjamin, este quiere, entonces, pensar una justicia sin derecho, "una justicia de los fines que no esté ya ligada a la posibilidad del derecho, en todo caso a aquello que se concibe siempre como universable" (Benjamin, 2001, p. 125). El orden de lo jurídico concibe tozudamente que los fines justos son fines de un derecho posible, no solo como universalmente válidos en virtud del atributo de la justicia, sino también como universables, lo cual contraría dicho atributo, porque, según Benjamin, los fines generalmente válidos y universables en una situación, no lo son para ninguna otra, pese a sus similitudes (p. 123).

Benjamin señala que antes y más acá de todo orden de derecho existe, después de todo, un motivo eficaz para considerar que incluso la mentalidad más renuente preferirá muy a menudo medios puros y no violentos para alcanzar soluciones pacíficas a los intereses humanos en discordia. Esto, por temor a las desventajas comunes que resultarían de un enfrentamiento de fuerza, sea cual fuere el vencedor. Ocurre de otro modo, dice Benjamin, cuando el litigio afecta a clases y naciones. Aquí, el orden superior que amenaza tanto al vencedor como al vencido permanece oculto para los sentimientos y opiniones de casi todos. No obstante, "la búsqueda de semejantes órdenes superiores e intereses comunes que se derivan de ellos, y que constituyen el motivo más persistente a favor de una política de los medios puros, nos llevaría 
demasiado lejos" (Benjamin, 2001, p. 119). Este autor pretende, pues, un orden de medios no violentos en las relaciones privadas y en las públicas que sustraigan la violencia del derecho, tal como ocurre en la huelga general proletaria, que no pretende fundar ni un nuevo Estado ni un nuevo derecho, sino pura y revolucionariamente otra forma de trabajo (Benjamin, 2001, p. 122).

Benjamin se opone a la violencia del derecho, a la tendencia intensiva de su propia efectuación. Su propósito es limitar la prisa y la impaciencia del derecho por ocupar el mundo en su totalidad. A propósito, pregunta Benjamin (2001):

¿Es posible una violencia que pueda abstraerse completamente del derecho? ¿Es pensable una violencia de otro tipo, que, por ello, no pueda ser el medio legítimo ni ilegítimo para fines justos? Aún más: ¿qué sucedería si una violencia ligada al destino empleara medios legítimos en insalvable contradicción respecto a fines justos? (p. 123).

Según Benjamin (2001), la cólera es ejemplo de una manifestación no mediada por la violencia, extraña a toda estructura de medio/fin. La violencia de la cólera no es un medio, sino una manifestación pura, sin vistas a un fin. $Y$ tal violencia se encuentra en el mito griego como pura manifestación de la voluntad divina (p. 123). Al respecto, el autor evoca el mito de Níobe como el mejor ejemplo. Níobe había engendrado siete hijos y siete hijas ${ }^{1}$. Desmesuradamente feliz y orgullosa de sus hijos, declaró un día que era superior a Leto, madre únicamente de Apolo y Ártemis. Las mujeres tebanas temieron la cólera de la diosa Leto y de sus hijos y, por tanto, quemaron incienso y se adornaron el cabello con ramas de laurel. Pero Níobe, nieta de Zeus y Atlante, temida por los frigios y reina de la casa de Cadmo, interrumpió el sacrificio y preguntó airadamente por qué Leto, madre de una hija hombruna y un hijo afeminado, era preferida a ella. Leto escuchó y ofendida pidió a sus hijos que la vengasen. Ambas divinidades armadas con sus arcos de plata y sus flechas mataron a los hijos de Níobe: Ártemis a las mujeres, y Apolo, a los varones. De estos, únicamente se salvaron una hembra y un varón. En la versión de la leyenda, tal como lo cuenta La Ilíada, los hijos de Níobe permanecieron tendidos en su sangre durante nueve días y nueve noches; al décimo, los propios dioses celestiales los sepultaron. Y Níobe, en su dolor, huyó al

1 Existen distintas versiones de esta leyenda: Homero dice que Níobe tuvo doce hijos; Hesiodo, veinte; Herodoto, cuatro; Safo, dieciocho; Euripides y Apolodoro, catorce: siete hijos y siete hijas (Graves, 2007, p. 346). 
monte Sípilo junto a su padre Tántalo, en el cual fue transformada en piedra por los olímpicos. Pero sus ojos siguieron llorando (Homero, 2007, canto 24, versos 605-617; Graves, 2007, pp. 344-346; Grimal, 2008, pp. 381-382).

Níobe conjura su propia fatalidad, no tanto por ofender el derecho, sino por desafiar al destino a una lucha, cuyo resultado engendra un nuevo orden de derecho. Según Benjamin, las acciones violentas de Apolo y Artemisa son algo más que un mero castigo a la transgresión de un derecho: su violencia establece más bien un nuevo orden de derecho. Los castigos divinos tenían, en efecto, poco de derecho conservador y, en cambio, más de derecho fundador entre los humanos. Sin embargo, esta violencia que proviene del destino y se agita sobre Níobe es profundamente ambigua en tanto funda, pero no destruye, ya que preserva la vida culpable de la madre, pese a derramar la sangre de sus hijos. Níobe será, por tanto, más culpable que antes, debido a la muerte de su estirpe, hasta convertirse en depositaria eterna y muda de esa culpa, límite entre humanos y dioses (Benjamin, 2001, p. 124).

Según Benjamin, el destino se presenta cuando se considera una vida como algo condenado, que luego se convierte en culpable (p. 134). Y esta es, justamente, la función que el derecho hereda del mundo demónico que lo precede y lo determina en sus procedimientos violentos: la de condenar la vida a una perpetua culpabilidad (Esposito, 2006, p. 50). Esta no se juzgará por ser culpable, sino que se la hará culpable para que pueda ser juzgada y condenada. Así, la violencia del derecho se encuentra íntimamente asociada al destino, por cuanto aplasta la vida contra la pared desnuda de este. Benjamin (2001) acusa al derecho de elevar las leyes del destino - la infelicidad y la culpa - como criterios de la persona, pues, según él, sería falso suponer que en el orden del derecho se encuentra solo la culpa, cuando toda culpa jurídica no es más que una desgracia (p. 133). El derecho condena a la culpa más que al castigo: "El juez puede ver el destino donde quiere; en cada pena debe infligir el destino" (p. 134). Y el destino es, con ello, el plexo de culpa de todo lo viviente. De este modo, la culpa no es el motivo, sino el resultado de la condena. Benjamin evoca las palabras de Goethe para decir: "Hacéis convertir el pobre en culpable"2.

2 Benjamin se refiere a la obra de Goethe Los años de aprendizaje de Wilhelm Meister, libro II, capitulo 13, verso 6. El poema integralmente dice: "Quien comió sin llanto su pan / quien en noches llenas de espanto / nunca roto se despertó / ese no te conoce. Cielo / tú decides nuestro vivir / tú haces deudor [culpable] al pobre / pues le procuras dolor / y penitencias en la tierra" (Goethe, 2006, pp. 258-259). 
Los héroes también luchan contra el destino, aunque con suerte diversa, pues conservan la esperanza de que algún día podrán entregar a los hombres un nuevo derecho. Aquí Benjamin apela al titán Prometeo, quién desafío al celeste Zeus robando algunas semillas de fuego en la rueda del sol, para donárselas a los hombres, a quienes el Juez Supremo del Olimpo ha querido eliminar. Mientras la gloria de Zeus reside en haber conquistado violentamente el poder supremo, la gloria de Prometeo se encuentra en haber ofrecido, por amor a los hombres, el fuego, la esperanza y las técnicas (García, 2009 , p. 116). Este titán suscita la misma fascinación que despierta el gran criminal en el pueblo, al querer fundar un orden de derecho distinto al establecido.

El enfrentamiento mítico entre el tirano y el rebelde representa la escena distintiva del poder: la obediencia dócil al mandato del más fuerte con tal de conservar la paz. En este sentido, es preciso acatar el nuevo orden y someterse con absoluta prudencia. Prometeo recuerda, en cambio, a los rebeldes titanes hijos de Urano y de Gea, que lucharon con extraordinaria violencia contra los hijos de Crono, hasta que fueron sometidos a tremendos castigos pero de singular grandeza (Hesíodo, 2005, § 620885; García, 2009, p. 90). El héroe evoca las acciones de los divinos Atlante y Tifón, los feroces adversarios de Zeus, hermanos brutales de Prometeo y compañeros en el dolor. En suma, la intervención es clara en afirmar el desacuerdo entre el titán insurrecto y el poderoso Zeus, en términos de sometimiento del castigado al opresor (García, 2009, p. 90).

Zeus, irritado por la acción del rebelde, ordenó que fuera amarrado al Cáucaso y mandó águilas a beber la sangre de su hígado perpetuamente renovado. Según Benjamin, esta violencia jurídica demuestra, en un sentido arcaico, que los castigos divinos, más allá de conservar el derecho, pretendían fundar un nuevo orden de poder. El nuevo mundo regido por Zeus está colmado de hechos de absoluto poder que se acometen por violencia y con violencia (prós bían o bíai). Por tal razón, Poder (Krátos) y Violencia (Bía) acompañan a Hefesto, el herrero divino y manipulador del fuego, en el suplicio que se impone sobre Prometeo. Los primeros aparecen como los fieles representantes del soberano de los dioses: Poder se presenta de un modo inconmovible, frío y cruel, mientras Violencia se muestra como un personaje mudo, un Kophòn prósopon, pero siempre en acto. En el comienzo de la escena trágica se escuchan los ruidos y los golpes de la ejecución. Hefesto, también operador de las órdenes del Supremo, se muestra profundamente conmovido ante el titán: “ $¡ A y$, Prometeo, gimo por tus penas! ¡Ay, oficio mío! ¡Cuánto te odio!” (Esquilo, 1986b, v. 45, 65). Pero estos lamentos son 
inexplicables para Poder y Violencia, justamente porque no entienden, no sienten, sino que ejecutan los mandatos de violencia proferidos por el tirano:

¿Por qué tardas y te apiadas en vano? ¿Por qué no aborreces al dios más odiado por todos los dioses, al que entregó a los mortales tu privilegio? ¿Andas vacilando y profieres gemidos por un enemigo de Zeus? ¡Ten cuidado, no sea que un día gimas por ti mismo! (Esquilo, 1986b, v. 35, 65).

Seguidamente se escuchan las órdenes absolutas de Poder:

Date prisa, entonces a encadenarlo, para que tu padre no vea que andas reacio. Cuando le hayas atado los brazos, dale al martillo con toda tu fuerza y déjalo clavado a las rocas.

Golpea con más fuerza. Apriétalo bien. No lo dejes flojo por ningún lado, pues es astuto para hallar salida incluso cuando es imposible.

Asegura este otro codo también, para que aprenda que a pesar de ser sabio es más torpe que Zeus.

Ahora, con fuerza, clávale el pecho de parte a parte con la fiera mandíbula de una cuña de acero.

¡Baja ahora aquí! Colócale un chincho en torno a los flancos.

Sujétale las piernas con anillos.

Golpea ahora con fuerza esos grilletes bien apretados, que es muy severo el juez de tus trabajos (Esquilo, 1986b, v. 35, 85).

El profesor García Gual (2009) describe a los personajes Poder y Violencia: “como mascarones, sin un trasfondo o interioridad, meros autómatas policiales, los servidores ideales del tirano". De esta modo, el odio de Poder hacia Prometeo no solo representa aquel que siente el justo contra el malhechor, sino también el rencor sordo del autómata hacia aquel que, en su transgresión al orden imperante, proclama su libertad para desobedecer las órdenes del tirano (García, 2009, p. 88). Así lo ratifican las últimas palabras de Hefesto hacia poder: "Conforme a tu figura, habla tu lengua" (Esquilo, 1986b, v. 75). 
Luego se marchan Hefesto, Poder y Violencia, y Prometeo solloza abandonado sobre su roca:

¡Mirad con qué clase de ultrajes desgarradores he de luchar penosamente por un tiempo de infinitos años! ¡Tal es la infame condena que inventó contra mí el nuevo jefe de los felices! ¡Ay, ay! ¡Me lamento por el presente y futuro dolor! ¿De qué modo algún día debe surgir el fin de estas penas. ¿Pero qué digo? Sé de antemano con exactitud todo el futuro, y ningún daño me llegará que no haya previsto. Debo soportar del modo más fácil que pueda el destino que tengo asignado, porque conozco que invencible es la fuerza del Hado. Pero no me es posible ni callar ni dejar de callar este infortunio, pues - idesgraciado de mí! - por haber facilitado un privilegio a los mortales, estoy bajo el yugo de estas cadenas (Esquilo, 1986b, v. 95-110).

Estas palabras resuenan en el coro de las vírgenes oceánidas que entonan el canto de la lamentación por la pasión del rebelde. Este canto compasivo y quejumbroso es altamente sobrecogedor y constituye uno de los más bellos fragmentos líricos del drama antiguo, pues presenta la compasión no solo por el titán, sino también por todos los hombres que viven en torno al Cáucaso y, luego, por toda la naturaleza en su conjunto (Romilly, 2010, p. 44; García, 2009, p. 90). De esta manera, las Oceánidas representan en el drama y en la crítica benjaminiana una forma de relación no jurídica y, por tanto, violenta, fundada en la cultura del corazón, en la sympátheia cósmica, cuya traducción castellana derivada de la versión latina compassio no refleja el sentido fuerte del término griego que significa "sufrir con", "compartir el dolor con". Justamente, las jóvenes ninfas, abatidas ante el nuevo orden de violencia y de injusticia, elijen sufrir el mismo dolor con el titán antes que abandonarle y acatar las órdenes del tirano. Ellas se dejan tragar por el mar junto a Prometeo (García, 2009, p. 90).

En efecto, las hijas nacidas de Océano y de Tetis cantan al unísono por el rebelde atado sobre la peña asolada frente al mar:

Viéndote estoy, Prometeo, y una niebla medrosa preñada de lágrimas ha nublado mis ojos al ver marchitarse tu cuerpo en la roca con ese ultraje de estar atado con nudos de acero [...] ¡Prometeo, tendría de hierro el corazón y él mismo estaría hecho de piedra quien por tus penas no compartiera contigo 
su indignación. No hubiera querido yo verlas, pues cuando las vi el corazón se me partió! (Esquilo, 1986b, v. 145, 150, 240, 245).

Y seguidamente se refieren a los mandatos del tirano:

Sí; nuevos pilotos tienen el poder en el Olimpo; y con nuevas leyes, sin someterse a regla ninguna, Zeus domina y a los colosos de antaño ahora él los va destruyendo $[. .$.$] ¿Qué dios tendrá un corazón tan insensible que disfrute con$ esto? ¿Quién no comparte la indignación por tus desgracias, aparte de Zeus? [El rencor de Zeus] ha hecho inflexible su mente y somete a su arbitrio a la estirpe de Urano, y no acabará hasta que sacie su corazón o hasta que alguien con mano astuta le arrebate su imperio inexpugnable (Esquilo, 1986b, v. 150, 160, 161).

La violencia sobre el divino Prometeo es objeto de una grave indignación entre las ninfas y los humanos, debido al ejercicio cruento del poder y la violencia del nuevo tirano. El poder del amo sobre los dioses y los hombres es reciente e irregular. Su dominio no se encuentra todavía afianzado, lo cual demanda prácticas de sujeción y de violencia jurídica severas y ejemplarizantes, pues la violencia mítica como creación de poder es creación de derecho y también es un acto de inmediata manifestación de la violencia (Benjamin, 2001, p. 124).

Según Benjamin, la función de la violencia en la creación jurídica es doble: por una parte, la fundación de derecho tiene como fin ese derecho que pretende implantar a partir de la violencia como medio; por otra, una vez establecido el orden jurídico, no renuncia, sin embargo, a su inmunidad e independencia respecto a la violencia, sino que se liga íntima e inmediatamente a ella en nombre del poder. El poder es, pues, el principio de toda instauración mítica del derecho, del cual derivan todas las prerrogativas de reyes y poderosos. Así, la igualdad entre hombres y Estados no existe desde la perspectiva de la violencia que solo puede garantizar el derecho. En el mejor de los casos, escribe Benjamin, existen violencias igualmente grandes. Y mientras exista el derecho, esta verdad, no solo de índole histórico-cultural, sino ante todo metafísica, perdurará mutatis mutandis (Benjamin, 2001, p. 125; 1991, p. 40). En suma, dice Benjamin que la manifestación mítica de la violencia inmediata, lejos de fundar una esfera más pura, se muestra profundamente idéntica a toda violencia del derecho; en consecuencia, se presenta igualmente corrupto respecto a su función histórica, cuya destrucción se convierte en una tarea (2001, p. 126; 1991, p. 41). 
En este momento de la crítica, Benjamin opone la violencia de Dios a la violencia del mito griego, idéntica a la violencia jurídica, que, a su vez, crea y conserva el derecho. El principio de toda instauración divina de un fin es la justicia; el poder, en cambio, es el principio de toda creación mítica del derecho. Así como Dios y mito se enfrentan en todos los ámbitos, se oponen también ambas violencias. La violencia de Dios es una manifestación puramente revolucionaria, capaz de paralizar a la violencia mítica: destruye el derecho en vez de fundarlo. Ella arrasa fronteras en lugar de constituirlas, es redentora y no culpabilizadora o expiatoria, golpea en lugar de amenazar. Definitiva y esencialmente, la violencia de Dios, en lugar de hacer morir por la sangre, hace morir sin verterla. La violencia mítica es violencia sangrienta sobre la vida desnuda, en nombre del poder, mientras que la violencia divina lo es sobre todo lo vivo y por amor a lo viviente, en nombre de la justicia (Benjamin, 2001, p. 126; 1991, p. 43). En este punto, Benjamin contrapone el juicio de Dios contra la tribu de levitas de Korah, a quienes destruye sin previa amenaza y sin derramar su sangre. El juicio de Dios afecta a los levitas privilegiados de un modo no sangriento, pero incruento y redentor.

En la sangre se define, pues, la oposición entre ambas violencias. Y es que la sangre, dice Benjamin (2001), es el símbolo de la vida desnuda, de la vida pura y simple, de la vida en cuanto tal. La violencia jurídica protege la vida desnuda, porque puede derramar su sangre en cualquier momento. La violencia divina destruye los bienes, el derecho, la vida y similares, pero nunca de modo absoluto en relación con el espíritu de lo viviente (Benjamin, 2001, p. 126; 1991, p. 43). Esta violencia, según el autor, no se manifiesta únicamente en las tradiciones religiosas, sino también en una expresión sacralizada de la vida cotidiana. Benjamin evoca el mandamiento "no matarás" como el imperativo divino que ordena el respeto del ser vivo, más allá del derecho, más allá del juicio (Derrida, 2002, p. 129). La persona o la comunidad deben observarlo incluso en las situaciones más extremas o excepcionales.

Así, dice Benjamin, lo entendió el judaísmo, que rechaza, por ejemplo, el asesinato por legítima defensa, ya que concibe la vida en su totalidad como algo sagrado. Benjamin entiende la sacralidad de la vida como vida justa, distinta a la mera vida natural, porque la vida del hombre no coincide de ningún modo con su vida desnuda, ni con la mera vida biológica que le asiste, ni con cualquier otro de sus estados o cualidades, ni siquiera en la unicidad de su persona corporal. Lo que es sagrado en la vida del hombre no es su mera vida, sino la potencialidad: la posibilidad de la justicia, la justicia de su vida. 
La violencia del más fuerte "es lo que hace del hombre una cosa en el sentido más literal, pues hace de él un cadáver" (Weil, 2005, p. 15). La fuerza que mata hace del hombre una piedra, tal como aconteció con Níobe transformada en risco, cuya figura parece llorar cuando los rayos del sol inciden en su capa de nieve invernal, o con Prometeo en la segunda versión kafkiana, en la que, aguijoneado por el dolor de los picos desgarradores del águila, se fue hundiendo en la roca hasta compenetrase con ella. Así también ocurrió con el musulmán de Auschwitz, que no vio ni conoció nada, que tocó fondo y se convirtió en "no-hombre”, “cadáver ambulante”, "muerto vivo", "hombre momia". El musulmán se presenta a través de una figura separada de cualquier posibilidad de testimonio, una suerte de cosa que, en su aislamiento, permite la asignación de cualquier identidad demográfica, étnica, nacional o política. Pero no solo en el mito o en los campos de concentración alemanes, sino desde siempre se muestran hombres y mujeres despojados de su condición. Ellos están destinados, desde el nacer mismo, a sufrir la violencia de la exclusión, el hambre, el frío. Sus vidas han sido desnudadas y convertidas en cadáveres antes de ser tocadas, incluso, por la armadura de la violencia.

\section{La justicia de la memoria}

En la octava tesis de Sobre el concepto de historia, Benjamin (2010c) escribe:

La tradición de los oprimidos nos enseña que el "estado de excepción en el que vivimos es la regla" [...] El concepto de historia al que lleguemos debe resultar coherente con ello. Promover el verdadero estado de excepción se nos presentará entonces como nuestra tarea, lo que mejorará nuestra posición en la lucha contra el fascismo. La oportunidad que este tiene está, en parte no insignificante, en que sus adversarios lo enfrentan en nombre del progreso como norma histórica. El asombro ante el hecho de que las cosas que vivimos "aún" posibles en el siglo veinte no tiene nada de filosófico. No está al comienzo de ningún conocimiento, a no ser el que la idea de la historia de la cual proviene ya no puede sostenerse. (p. 24)

Benjamin establece aquí una relación entre la religión, a partir de la categoría "tiempo mesiánico", y el derecho público, en virtud del término "estado de excepción”. La excepción denota aquello que se encuentra excluido de la norma general, en tanto 
asume la forma de la suspensión respecto al ordenamiento jurídico. El estado de excepción no es, por tanto, el caos que precede al orden jurídico, sino la situación que resulta de la suspensión jurídica. En este sentido, el tiempo mesiánico tiene la forma de estado de excepción: "En el tiempo del Mesías sale a la luz el fundamento oculto de la ley, y la ley misma entra en un estado de perpetua suspensión" (Agamben, 2007, p. 327). Esta relación benjaminiana entre lo mesiánico y lo jurídico permite, según Agamben, evidenciar el carácter particular del primero en su relación con el segundo, en tanto el acontecimiento mesiánico denota, tanto en el ámbito judío como en el cristiano o shiita, una transformación radical de todo el orden de la ley. El reino mesiánico es el concepto límite de la experiencia religiosa: "El Mesías es la figura en el cual la religión se enfrenta con el problema de la ley, y hace con ella una decisiva rendición de cuentas" (Agamben, 2007, p. 327).

En su Fragmento teológico-político, Benjamin (2010) afirma que es el Mesías mismo quien completa todo acontecer histórico, en el sentido de que es él quien redime, completa y crea la relación del acontecer histórico con lo mesiánico mismo (p. 206). El tiempo mesiánico es el tiempo de ahora (ho nyn kairós). Y, justamente, porque este es cronológicamente indeterminado - la parusía, el retorno de Cristo que marca su fin, es cierta y cercana, pero incalculable-, tiene la capacidad de relacionarse con cada instante del pasado y de hacer de cada momento o episodio bíblico una profecía o una prefiguración del presente. Así, Adán, a través de quien la humanidad recibió la muerte y el pecado, es "tipo" o "figura" del Mesías, que trae a los hombres la redención y la vida (Agamben, 2011, p. 28). Esta comprensión benjaminiana alude a otra forma de leer la historia, de "citarla", según una necesidad que no proviene en modo alguno de su arbitrio, sino de una exigencia a la que no podernos dejar de responder críticamente. En palabras de Agamben (2010), “es como si esa luz invisible que es la oscuridad del presente proyectase su sombra, adquiriese la capacidad de responder a las tinieblas del ahora" (p. 29).

Esta comprensión de la historia tiene un carácter verdaderamente subversivo respecto al poder, pues destruye el canon de las plausibilidades vigentes y de las supuestas normalidades de nuestro mundo vital. A la luz de la memoria, el poder social, político y jurídico no pueden justificarse sin más, porque deben preguntarse hasta qué punto son los causantes de la opresión y sufrimiento de aquellos que han vivido en un estado de excepción permanente. En efecto, el teólogo J. B. Metz (1979) afirma que existen evocaciones del pasado peligrosas y desafiantes para el orden del presente. 
Son como tribulaciones amenazantes e imprevisibles que vienen del pasado con contenido de futuro. "No por casualidad la destrucción del recuerdo es una típica medida de todo gobierno totalitario" (Metz, 1979, p. 120), porque la reducción de la vida a la mera vida natural comienza mediante el despojo de sus recuerdos. Toda dominación tiene ahí su principio; y toda resistencia contra la opresión se nutre de la fuerza subversiva del sufrimiento evocado (Metz, 1979, p. 121). La justicia, más allá de la violencia del derecho, permite rememorar el sufrimiento de los oprimidos, de los vencidos, de los sojuzgados de la historia. Es una especie de antihistoria que pone su acento en el sufrimiento y en la vida lograda y digna de ser vivida como vida justa.

Justamente, Benjamin (2001) advierte una nueva época histórica que se alza sobre las formas de derecho míticas encarnadas en la violencia del derecho de Estado, sobre la destitución del orden legal y las violencias que se le subordinan y, a la vez, a las que ese orden está subordinado (p. 128). Allí donde la violencia limpia y pura toma el lugar de la violencia mítica, se deduce la existencia posible de la violencia revolucionaria como manifestación de pura violencia. De nuevo, dice Benjamin (2001): "Están a disposición de la pura violencia todas las formas eternas que el mito ha bastardeado con el derecho" (p. 129). La violencia fundadora de derecho y la violencia conservadora son igualmente reprobables. La violencia divina, en cambio, es insignia y sello, nunca medio de sacra ejecución, que podría llamarse la reinante. La violencia mesiánica adopta aquí la forma de lo redentor, de lo salvífico o, dicho de otro modo, el lugar donde se suspenden los terrores de un derecho y una política fundados en la violencia figurada en el estado de excepción y en la reducción de la vida justa o común a la mera vida natural, a la vida desnuda. De este modo, lo mesiánico revelará que la violencia como medio del derecho ha conducido, desde su origen, al aplastamiento de la vida. Al mismo tiempo, lo mesiánico permitirá disolver el vínculo entre la violencia jurídica y la sacralidad de la vida, dejando emerger su fuerza pura como violencia revolucionaria.

Al igual que Vladimir y Estragón esperan infinitamente a Godot, la fe de las víctimas posibilita la espera del Dios de la memoria infinita, del tiempo mesiánico en que Él redimirá a los muertos y hará justicia a la excepción padecida. El Mesías abraza los gritos de protesta y resistencia de las víctimas frente al verdugo y la esperanza de la justicia universal, plena y cumplida (Mardones, 2003, p. 228). Dios se afirma como guardián del desasosiego del mundo de los vivos y del mundo de los muertos. Desde algunas voces de los sobrevivientes, la esperanza en la resurrección de los ausentes 
asume la expresión de un ansia de justicia universal, que será impartida por el poder de Dios; un poder que, según la perspectiva apocalíptica, tampoco deja tranquilo el pasado. El mensaje apocalíptico les confirma a ellas, a las víctimas, una vez más, que ante Dios nada está asegurado, en contra del modo en que solemos reconciliarnos con el sufrimiento pasado y tranquilizarnos con el olvido.

Las preguntas de Vladimir resuenan en nuestro presente: “Qué diré acerca de este día? ¿Qué he esperado a Godot, con Estragón, mi amigo, en este lugar, hasta que cayó la noche?" (Beckett, 2007). Mientras se espera en el instante presente a Dios, a Godot, al amor, a la muerte, el tiempo continúa en movimiento sucediéndose instantemente:

Un día, ¿no le basta?, un día como otro cualquiera, se volvió mudo, un día me volví ciego, un día nos volveremos sordos, un día nacimos, un día moriremos, el mismo día, el mismo instante, ¿no le basta? El día brilla por un instante, y, después, de nuevo la noche. ¡En marcha! (Beckett, 2007, p. 120).

Un día como cualquiera y como todos los demás, un día en el que se espera, un día en el que suceden fugazmente los hechos de horror y sufrimiento guardados en el pasado; es, a pesar de ello, el tiempo del ahora. El tiempo del presente, del ahora, es entendido, desde la perspectiva benjaminiana, como aquello que tiene el pasado de vivo en el presente, es decir, la actualidad de un momento pasado dado por perdido. Los horrores sucedidos en el presente se hallan contenidos en los palimpsestos de las catástrofes pasadas, ya que estos contienen las claves para descubrir las preguntas de nuestro tiempo. Benjamin evoca el pasado en la forma de una astilla mesiánica: la astilla en la memoria del presente horada su fina construcción, absorbiendo contemplativamente la injusticia del pasado, que cuartea la seguridad del presente construido sobre el olvido. La grave contemplación de aquellas generaciones excluidas y la absorción de sus voces demandantes de justicia conducen a interrogar el presente, anulando la espera resignada y planteando la demanda de una justicia de la memoria.

Este encuentro entre el pasado y el presente permite la creación de un hecho, más que su reconstrucción. El hecho de crear el presente a partir de la conciencia crítica del pasado habilita para salvarlo, justamente porque el ahora implica una exigencia de redención de todas aquellas injusticias que continúan vigentes y claman por justicia. De este modo, el pasado olvidado se presenta ante las generaciones presentes y por venir como un imperativo de justicia: la generación de los abuelos humillados cuenta 
con la de sus nietos pera denunciar la excepción en la que han vivido durante años (Benjamin, 2006, pp. 70-80). En suma, la concepción benjaminiana de la historia vinculada al mesianismo permitirá, además de destruir el orden de poder y violencia legal que somete la vida natural, instaurar un orden de justicia más allá del derecho, que permita actualizar y transformar nuestro presente a partir del pasado olvidado.

De esta manera, la crítica benjaminiana pretende exceder la comprensión según la cual los conflictos humanos son irresolubles, en principio, sin recurrir en absoluto a la violencia del derecho. Benjamin propone otros medios, medios puros, alternos al poder y exentos de violencia. Las uniones no violentas entre personas privadas son posibles allí donde la cultura del corazón pone a disposición de los hombres los medios puros del "mutuo entendimiento", o sea, el lenguaje. Esto confirma, según Benjamin, que existe, precisamente en el ámbito privado o de la intención personal de un convenio no violento, una legislación completamente inaccesible a la violencia. Sus precondiciones subjetivas son cortesía, sincera afinidad, amor a la paz, confianza y todo aquello que permita ser incluido en el contexto de la justicia como memoria.

En esta misma dirección y desde el mismo origen judío, Weil plantea una justicia completamente distinta al derecho. Esta oposición entre los términos se debe a la relación de cada uno respecto a la fuerza. Weil considera al derecho como algo fundamental en la estrategia del que impone la fuerza. No siendo un límite para la fuerza, el derecho se convierte ahora en una máscara de la fuerza, que obliga coactivamente a obedecer el mandato de la autoridad suprema que se pretende legítima (Greco, 2010, pp. 1112). Weil también propone superar la tradición jurídica a través de la asunción del otro. El principio fundamental de la justicia pasa, entonces, por el amor sobrenatural, que impide ejercer el dominio sobre los demás. Entre el amor y la justicia existe una íntima relación que debe ser explorada en relación con la justicia como memoria.

\section{Referencias}

Agamben, G. (2007). El Mesías y el soberano. El problema de la Ley en Walter Benjamin. En La potencia del pensamiento. Ensayos y conferencias. Buenos Aires: Adriana Hidalgo.

Agamben, G. (2010). Medios sin fin. Valencia: Pre-textos. 
Agamben, G. (2011). ¿Qué es lo contemporáneo? En Desnudez. Buenos Aires: Adriana Hidalgo.

Benjamin, W. (1991). Para una crítica de la violencia. Madrid: Taurus.

Benjamin, W. (2001). Para la crítica de la violencia. En Suhrkamp (Ed.). Ensayos escogidos (pp. 109-129). México: Coyoacán.

Benjamin, W. (2010a). Destino y carácter. En Tiedemann, R. y Schweppenhäuser, H. (Eds.). Obras (vol. 1, libro II, pp. 183-206). Madrid: Abada.

Benjamin, W. (2010b). Fragmento teológico-político. En Tiedemann, R. y Schweppenhäuser, H. (Eds.). Obras (vol. 1, libro II, pp. 206-207). Madrid: Abada.

Benjamin, W. (2010c). Tesis sobre la historia y otros fragmentos. Bogotá: Desde Abajo.

Beckett, S. (2006). Esperando a Godot. Barcelona: Tusquets.

Bojanic, P. (2010). La violencia divina en Benjamin y el caso de Korah. La rebelión contra Moisés como primera escena del mesianismo. Acta poética, 31(1-2), 135-161.

Cohen, H. (2004). La religión de la razón desde las fuentes del judaísmo. Barcelona: Anthropos.

Derrida, J. (2002). Fuerza de Ley. El fundamento místico de la autoridad. Madrid: Tecnos.

Esposito, R. (2005). Immunitas. Protección y negación de la vida. Buenos Aires: Amorrortu.

Esposito, R. (2006). Bíos biopolítica y filosofía. Buenos Aires: Amorrortu.

Esquilo (1986a). La orestiada. En Tragedias (pp. 377-538). Madrid: Gredos.

Esquilo (1986b). Prometeo encadenado. En Tragedias (pp. 539-582). Madrid: Gredos.

Forster, R. (2009). Los hermeneutas de la noche. Madrid: Trotta.

Galindo, A. (2005). Política y mesianismo. Giorgio Agamben. Madrid: Biblioteca Nueva.

García, C. (2009). Prometeo: mito y literatura. Madrid: Fondo de Cultura Económica. 
Goethe, J. W. V. (2006). Los años de aprendizaje de Wilhelm Meister. En Siguan, M. (Ed.). Narrativa (pp. 131-732). Córdoba: Espasa \& Almuzara.

Graves, R. (2002). Los mitos griegos 1. Madrid: Alianza.

Graves, R. (2007). Los mitos griegos 2. Madrid: Alianza.

Greco, T. (2010). Derecho y justicia en Simone Weil. En Bea, E. (Ed.). Simone Weil. La conciencia del dolor y la belleza. Madrid: Trotta.

Grimal, P. (2008). Diccionario de mitología griega y romana. Barcelona: Paidós.

Hesíodo (2005). Teogonía. Madrid: Alianza.

Homero (2007). La Ilíada. Madrid: Austral.

Jerade, M. (2007). De la violencia legítima a la violencia revolucionaria. Acta poética, 28(1-2), 257-278.

La Fontaine, J. de (2009). Fábulas de la Fontaine. El lobo y el cordero. Bogotá: Educar.

Mardones, J. M. et al. (2003). El neo-conservadurismo de los posmodernos. En torno a la posmodernidad. Barcelona: Anthropos.

Mate, M. R. (1991). La razón de los vencidos. Barcelona: Anthropos.

Mate, M. R. (2006). Media noche en la historia. Comentarios a las tesis de Walter Benjamin "Sobre el concepto de Historia". Madrid: Trotta.

Metz, J. B. (1979). La fe en la historia y la sociedad. Esbozo de una teología política fundamental para nuestro tiempo. Madrid: Cristiandad.

Metz, J. B. (1999). Por una cultura de la memoria. Barcelona: Anthropos.

Minkowicz, G. et al. (2010). Introducción a las fuentes del derecho hebreo. Buenos Aires: Lilmod.

Montaigne, M. (2008). Ensayos completos. Madrid, Cátedra.

Mosés, S. (2007). El Eros y la Ley. Lecturas bíblicas. Buenos Aires: Katz.

O’Nell, E. (1987). A Electra le sienta el luto. Barcelona: Hyspamérica. 
Pascal, B. (1981). Obras: pensamientos, provinciales, escritos científicos, opúsculos y cartas. Madrid: Alfaguara.

Pascal, B. (2009). Pensamientos. Madrid: Alianza.

Romilly, J. de (2010). La Grecia antigua contra la violencia. Madrid: Gredos.

Scholem, G. (2011). Walter Benjamin- Gershom Scholem. Correspondencia 1933-1940. Madrid: Trotta.

Sorel, G. (2005). Reflexiones sobre la violencia. Madrid: Alianza.

Todorov, T. (2000). Los abusos de la memoria. Barcelona: Paidós.

Vernant, J. P. (1993). Mito y pensamiento en la antigua Grecia. Barcelona: Ariel.

Weil, S. (2005). La fuente griega. (J. Escartín \& M. Escartín, trad.). Madrid: Trotta.

Weil, S. (2007). Escritos históricos y políticos. Madrid: Trotta.

Zambrano, M. (2007). El hombre y lo divino. Madrid: Fondo de Cultura Económica. 